\title{
Politeness Aspects of ELF Interaction: a Discussion of a Conversational Encounter from the VOICE Corpus
}

\section{Milan Ferenčík}

The paper is an attempt to apply the discursive approach to politeness to the micro-analysis of a conversational encounter in which English is used as a contact language, or lingua franca (ELF). The analysed conversational data are taken from the Vienna-Oxford International Corpus of English (VOICE) and represent a common ELF setting, viz. an interaction of two international students who share their experience of and/or concern with safety as an important aspect of their student life. In order to understand the nature of norms to which the participants orient, it is necessary to look at the status of ELF vis-à-vis other "Englishes" in the classic Kachruvian modelling of World Englishes. The paper argues that, rather than being another regional and/or social variety of English, ELF is a functional variety (register), a principal communicative resource which users creatively employ and forge to ensure mutual intelligibility and sociality, i.e., warrant both communicative and social goals. It is further argued that, while engaged in the interaction, participants carry out relational work in which they negotiate their mutual relationships and construe norms of appropriateness "here and now", i.e., within the immediate community of practice. It is against the background of this normality, or unmarkedness, that they evaluate each other's behaviour as (non/im/over)polite, rude, etc. In accordance with the post-modernist/constructivist politeness modelling it is also argued that politeness is subject to discursive negotiation and covers that slice of the spectrum of relational work which is evaluated by the hearers as going beyond the appropriate (unmarked, non-polite) behaviour. As to their politeness aspect, the analysed ELF situation is characterized by the participants' effort to accommodate each other and to establish and maintain a mutually cooperative environment.

\section{Introduction}

Alongside the diminishing significance of physical boundaries, increasing exchange of goods and information and growth of international travel at 
an unprecedented rate, it is also the rise and establishment of English as a global language that indexes the current processes of globalization. Labelled variously to mark its emerging transnational role as global, international, world, or lingua franca, English currently serves as the vehicle of globalization in many areas, as a tool for breaking down communication barriers and marking speakers' identities, for spreading existing and creating new knowledge. It is to be noted that, rather than being freely interchangeable, these labels are value-laden in that each of them points to a particular discourse which conceptualizes the nature and role of English differently. In the present study I deal with the "lingua franca" English (ELF), a new "kind" of English which has recently been conceptualized and which has altered the current map of Englishes in the world most radically. Newly emerging ELF discourse raises several important issues regarding the sociolinguistic status, especially whether or not it is yet another variety on a par with other geographical varieties, and, if so, whether there are any recurring structural properties which set it apart as a homogeneous variety from other varieties, whether or not the enormous variability of unstable, ever-changing communities of its (non-native) users has any influence on its characterization, and, finally, whether or not it is necessary to redraw the classic Kachruvian modelling of world Englishes which, despite all its limitations, will be used as a springboard for the present discussion. In the paper I attempt to tackle the following questions: How does ELF relate to the current models of world Englishes? Is ELF a variety for the expanding circle countries in its own right or a functional variety (register)? And, finally, how does politeness as a pan-human phenomenon manifest itself in an effort to accommodate ELF conversationalists from different linguacultures?

\section{Modelling World Englishes}

The World Englishes discourse has enriched scholarship with new concepts and approaches. The classic attempts at conceptualizing the status of English in the world have been elaborated by Strevens (33), Kachru (356), McArthur (97), Modiano (International 25, Standard 10) and Graddol (110); due to its simplicity, comprehensiveness and flexibility, it is Kachru's model which remains to stand out as the principal point of reference within the discourses revolving around the global distribution and/or spread of English. 


\subsection{Classic models}

Kachru's (Teaching 356) inference-rich concentric model (first proposed in 1985 ) is a centrifugal representation of the situation within "world" Englishes whose "inner", "outer" and "expanding" circles reveal their origin ("native" and "non-native"), type of spread (the inner "1st and 2nd diasporas" and the foreign language learning margin), manner of acquisition and functionality ("English as a native language", ENL; "English as a second language", ESL; "English as a foreign language", EFL) and sources of normativity ("normproviding", "norm-developing" and "norm dependent") respectively. While the model serves well the purpose of a general orientation within the reality modelled, it is not immune against certain problems, which are due to the fact that the sociolinguistic reality is far from being as clear-cut as outlined. Briefly, first, there is obviously no one single ENL variety, second, there are grey transitional areas between the circles; in fact, Englishes within circles are on the move: while Englishes in the "outer circle" are striving to be recognized as legitimate $1^{\text {st }}$ native languages, several European countries have already embarked on the transition course from their EFL to ESL status), third, there are shady areas within the circles themselves: "outer circle" countries may include speakers of ENL. Hence, no matter how useful the model is, its stability is only relative. What is more, the model implies the primacy of native varieties which arises from the assumption of the speakers' inherited title to these varieties, and, still further, it does not consider speakers' level of proficiency and the style/register variation. A radical reassessment of Kachru's is offered by Modiano's (International 25, Standard 10) and Graddol's (110) centripetal models which are based on the speaker's degree of proficiency in English rather than on their origins. In Graddol's model (110), for example, the "functionally native" speakers, i.e., those who are competent across wide ranges of uses of English regardless of their origin, form the model's core.

\subsection{ELF - a pidgin, an interlanguage, a new variety, or a register?}

Despite the fact that each of the alternative models engenders new problems, such as the boundaries between language proficiency levels along with the issue of an authority to pass that judgement, they are illustrative of the complexity of the situation within the world Englishes which arises from the fact that no single language in the history of humankind has been put to so many uses across space, time and range of functions within a single person's lifetime. The most striking off-shoot of the global spread of English is that 
the number of its users for whom it is neither a native language (NL) nor a second language (SL) but who use it as a contact language among themselves, i.e., as lingua franca, has risen most dramatically over the past few decades (cf. Gibová 47). The question that immediately arises is how to integrate ELF into the Kachruvian tripartite model. Is it simply a new name for the EFL (Figure 1a), or a newly emerging supraregional variety (another "New English") that transcends all three circles and serves as "a 'contact language" between persons who share neither a common native tongue nor a common (national) culture, and for whom English is the chosen foreign language of communication" (Firth 240); cf. Figure 1b, or a functional variety/register of English available to all users of English across the circles in intercultural communication (Figure 1c)?
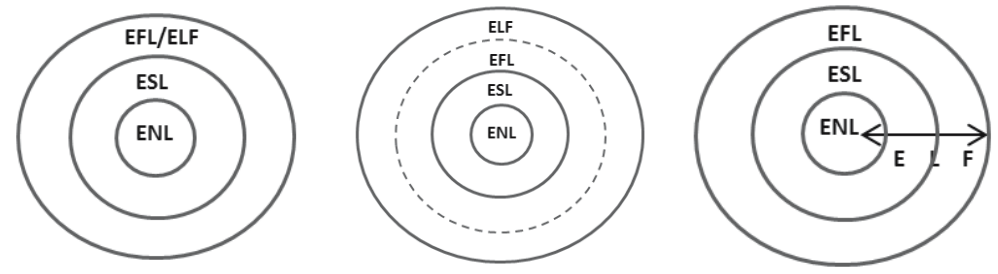

Figure 1: ELF as a/ a new name for EFL, b/ another "New English", c/ a functional variety of English, or register.

As far as looking at ELF as a pidgin, i.e., a kind of restricted code is concerned, this possibility can be ruled out since ELF is elaborate on each level of its structure and may be used to cover a wider range of functional uses, from casual conversations to specialized talks in multinational business settings. Similarly, it can be argued against the claim that ELF represents an interlanguage, i.e., a learner-language at a certain stage of the languagelearning process: ELF speakers are de facto "users", and only secondarily also learners (to the extent to which people are life-long learners of any language, including L1). However, once one adopts the view that ELF is "de-owned" from its native speakers, there is no need to maintain the ideal native-speaker (NS) norm with which to measure ELF users' production and to evaluate it in terms of deviation from it, and to expect that this production should approximate that of the NS's in order to be considered acceptable. In fact I maintain that, rather than being "learners" or finding themselves somewhere "in-between" their L1 and L2 (English), ELF speakers are more 
or less competent "users" of a functional variety of English which forms a part of their verbal repertoire and which they employ as a "language for communication" (House 559) within multilingual settings. Accordingly, ELF may be approached as a special register of English which cuts across all Kachru's circles and which, although being at a disposal to every member of the global English-language community, including NSs, it is mainly used among the Expanding Circle speakers.

Treating ELF as a use-related variety (functional register) helps us overcome the problem of having to offer a thorough structural description of its linguistic features; there being no stable community of speakers as a setting within which a distinct homogeneous variety could emerge has caused the existing ELF linguistic descriptions to focus rather on the features which enable ELF speakers to communicate successfully or unsuccessfully (for pronunciation features see the "lingua franca core" in Jenkins 147-148, for the lexico-grammatical features see Seidlhofer 220). Since ELF situations are characterized by fluctuating communities and/or individuals of often unpredictable socio-cultural memberships which emerge and dissolve much more easily, it seems that their ephemeral nature in principle precludes the emergence of common features on the lexico-grammatical level and that these will accumulate on the level of communication strategies (pragmatics) as the manifestation of an effort to accommodate a partner from different ELF backgrounds. Indeed, the research focusing on the pragmatic and discourse levels of ELF interactions suggests that "what unifies lingua franca speech is communication strategies rather than the result of any structural convergence" (Mollin 45).

To conclude this section I propose that ELF does not constitute yet another separate (non-native) variety of English but rather a functional variety/register which is employed as a common code for communicative interactions whose participants cannot avail themselves of their mother tongues and which covers various domains (academia, science and technology, medicine, etc.) and communicative functions (conveying information, generating new knowledge, socialisation, etc.). Its specific linguistic features described in ELF research (such as dropping $3^{\text {rd }}$ person singular $-s$ ) do not form a coherent system that would be on a par with some well-established L1 or L2 varieties of English; what is more, it seems they are not even "endemic" to ELF, as they mark also other, Inner and Expanding circle, varieties of English.

Research into ELF has emerged as a vibrant strand within applied linguistics where a heavy focus is placed on the systematic NNS Englishes corporabased linguistic description of ELF varieties, for example VOICE (Vienna- 
Oxford International Corpus of English) and ELFA (English as a Lingua Franca in Academic Settings). Since it may be assumed that in ELF encounters which, as a rule, involve participants of uneven degrees of language proficiency who strive for maximum communicative efficiency, goal-orientedness and mutual co-operation, it is the pragmatic level which may offer no less interesting observations. In fact, ELF studies have offered some intriguing findings regarding the strategies used to cope with language deficiencies, such as overt collaboration in the construction of meaning, code switching, the "let-it-pass" and "make it normal" techniques (Firth), simplification (regularization) and complexification (repetition and reformulation) at different levels (cf., for example, Hülmbauer et al. 32). In the present paper I focus on the description of these strategies from the perspective of pragmalinguistic Politeness Theory, which I briefly outline in the following section.

\section{Politeness theory}

Since its establishment as an autonomous field of research within pragma/ sociolinguistics, Politeness Theory has gone through the periods of rapid growth and maturation until it has found itself in a deadlock of a dispute over some of its basic tenets, and on a threshold between two research paradigms, viz. traditional/modernist, and post-modernist. While on the one hand its foundational studies especially by Lakoff, Leech and Brown and Levinson have generated a wealth of empirical research testing their theoretical underpinnings, their premises have drawn thorough criticism and incited attempts at their elaborations and/or revisions. Understandably, the bulk of this criticism was levelled against the most elaborate of the models, viz. Brown and Levinson's groundbreaking publication and their rationalist and universalist conceptualization of politeness as a set of strategies aimed at offsetting potential partner's face-loss. The most radical criticism came from the post-modernist approaches formulated thus far most coherently by Eelen, R. J. Watts and M. Locher who treat politeness as a discursive concept. In this perspective, judgements of (im)politeness are not a matter of the speaker's intentions (and the analyst's predictions) but are seen as being nested in the hearer's evaluations, as discursively struggled over by participants themselves in on-going interactions. Accordingly, politeness is not conceived of as an "objectively" existing phenomenon, as is maintained by the mainstream (or "second-order/politeness ${ }_{2}$ ) theories, but as a participants' construct (hence it 
is a "first-order/politeness" notion) over whose content they have discursive dispute, or "struggle". I can offer here only a brief outline of the main tenets of the post-modernist/post-pragmatic modelling of politeness while entirely skipping the discussion of the classical pragmatic approaches.

\subsection{Discursive approach to politeness}

In Locher and Watts' conceptualization of politeness, negotiation of (Goffman's notion of) face takes place among individuals within what they call relational work (cf. Figure 3), which "comprises the entire continuum of verbal behaviour from direct, impolite, rude or aggressive interaction through to polite interaction, encompassing both appropriate and inappropriate forms of social behaviour" (10-11). Being the most radical departure from the canonical (pragmatic) politeness modelling, it sees polite behaviour as constituting only a relatively small part of the entire continuum of relational work, and that is that part of politic (i.e., appropriate) behaviour which "is equivalent to giving more than is required by the expected politic behaviour" (Watts 130; my emphasis). Thus, politeness is evaluated as a possible surplus to what is expected, unmarked, appropriate in the given context; hence interpersonal interaction is seen not as an arena in which people behave in either polite or impolite way but most commonly in an appropriate (politic) way.

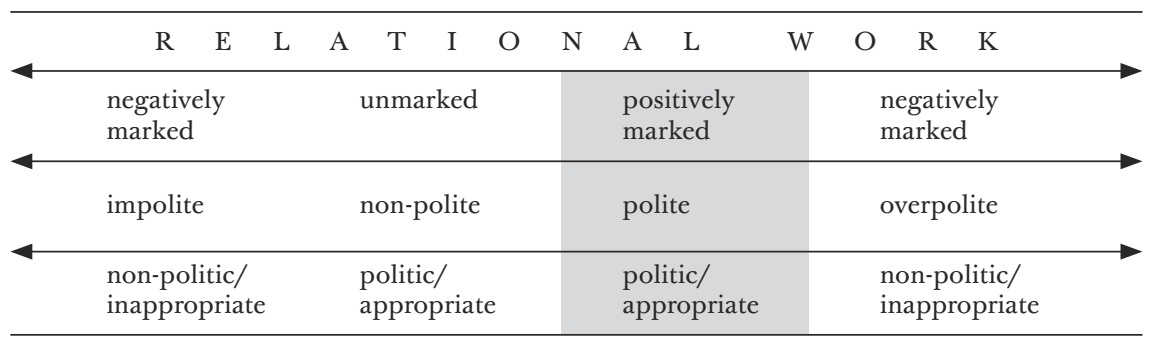

Figure 2: Relational work and politeness (Locher and Watts 12)

It would be fair to admit that, while solving certain problems of the "traditional" politeness paradigm, the discursive approach to politeness opens several problematic areas, such as its proclaimed ability to stand up to the claim of the necessity for politeness research to focus on first-order politeness (or politeness ${ }_{1}$ ) with the concomitant neglect for the need, and feasibility, of the second-order Politeness Theory, the status of participants' 
vs. analysts' perspectives, the utility of the categories of relational work, the operationalization of the definition of politeness, giving up the explanatory and predictive aspirations of theorization (cf. the claim that politeness research should focus on how and where the participants dispute over the notion of politeness rather than on why they do so). Among the critiques of post-modernist approach it is the Terkourafi's which pointed out a possibility of reconciliation of the traditional and post-modern approaches which, as she suggests, are in fact mutually complementary "at different levels of granularity" (Terkourafi 237), i.e., at the macro- and micro-levels respectively. I view the two politeness paradigms as crystallizations of quantitative and qualitative research traditions within social sciences, with their largely differing, albeit complementary, philosophical-methodological underpinnings and agendas. A deeper, and lengthier, analysis of the approach is, however, beyond the scope of the present paper.

\subsection{My approach to politeness}

In order to suggest that the perlocutionary effects of over-politeness are comparable to those of impoliteness (rudeness), in his introduction to Watts et al. (xliii), a republished version of the volume first issued in 1992 which heralded the discursive politeness paradigm, Watts presents an altered diagram in which the two end-points of the spectrum (as presented in Figure 2) meet. As an elaboration of this proposal I offer yet another diagram in which I combine several continua which overlap within relational work while adding to them an extra layer of (un)intentionality which, as I believe, is decisive in discerning rudeness (see Figure 3 further below). In this post-modernist/constructivist conceptualization of politeness, I approach politeness as being nested within the larger spectrum of relational work (in the diagram represented as a full circle), and that is as its relatively small part (the shaded area); the largest section of relational work is represented by the politeness-neutral (nonpolite/politic) behaviour, which is, for the given situation, evaluated by those involved in interaction as appropriate, non-salient, hence unmarked. Although I propose separate definitions for the respective areas of the relational work, here I offer the definition of politeness only:

[Politeness is] a (perlocutionary) effect of the speaker's (non)verbal behaviour upon the hearer who evaluates it positively as going (intentionally or unintentionally) beyond the norms of behaviour appropriate to a given situation within a particular community of practice, who sees its motivation 
in the speaker's effort to demonstrate positive concern for his/her face needs and who may display this evaluation in the sequential design of the unfolding interaction. (Ferenčík 73)

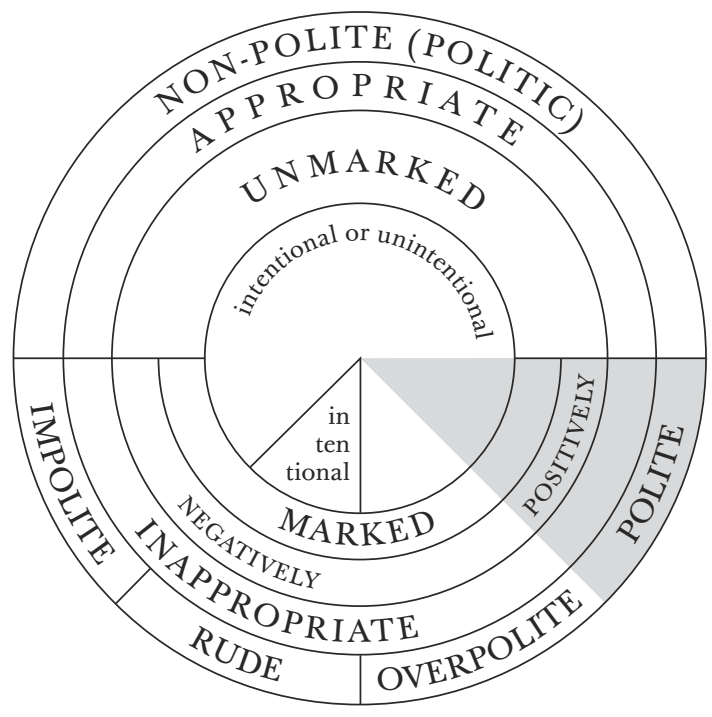

Figure 3: Politeness within relational work

From its wording it is evident that this is a first-order definition of politeness which is the hearer's (not the speaker's) notion, hence it relies on an evaluation of a speaker's behaviour by the hearer. As I see it, this evaluation is made against the norms of appropriateness which are flexible, emergent and coconstituted within a given Community of Practice (CofP; cf. Wenger; Eckert and McConnell-Ginet). Politeness is then seen as that portion of relational work which goes beyond what is expectable on the background of the norms of appropriateness in a given situation within a CofP; hence, it is evaluated by the hearer as a (non-obligatory) surplus to what is appropriate, as "a form of extra "linguistic payment" (Watts 152). Obviously, the borderlines between the categories of behaviour are flexible, permeable and negotiable as they are set by the participants themselves in the course of interaction. Further, (im/over)politeness, rudeness, etc., do not inherently reside in any particular forms of verbal (lexico-grammatical) or non-verbal behaviour, though certain 
forms of behaviour may warrant such evaluations ("expressions of procedural meaning"; Watts 180).

\section{Analysis}

\subsection{Data and methodology}

The three theoretical-methodological pillars of the present paper applied to the analysis of the selected ELF data are the post-pragmatic politeness theorization, the notion of Community of Practice and Conversation Analysis. These mutually-interlocking approaches are applied to the analysis of a single ELF interaction which is taken from the VOICE corpus (accessed at http://www.univie.ac.at/voice), the first large-scale database of ELF empirical material amounting to 1 million words (120 hours of recorded and transcribed interactions) including app. 1250 mainly European speakers of 50 different $\mathrm{L} 1$ backgrounds and covering different speech events ranging from professional to private settings. The corpus is a result of a project aimed at addressing an imbalance between the currently predominant number of ELF speakers worldwide and the lack of systematic linguistic description of ELF interactions.

The data selected for analysis represent a conversational encounter, a quintessential CofP in ELF communication. For the reasons of economy and greater surveyability I have made certain adaptations to the original "derived TXT version" of the transcript in which I removed original separate tags for each line. Also, as overlapping speech is essential in politeness phenomena-oriented research, I have made certain adjustments to mark the location and amount of overlappings. My main argument is that much of the behaviour that would be within the traditional (modernist) politeness paradigm assigned to the category of polite is not evaluated as such by the participants themselves; instead, it is perceived rather as merely appropriate given the norms which develop within the respective CofP.

As it is the conversation-analytical approach which is particularly well-suited for the examination of the entire stretches of authentic interaction and for tracking down how participants display their interpretation and/or evaluations of each other's actions, I choose it as a principal methodological tool. My approach is then characterizable as a bottom-up and data-driven one which is applied to the corpus of naturalistic data and which uses qualitative analysis methodology, viz. close analysis of verbal interaction in search of 
the "occasions when participants themselves display an orientation to actions as impolite [polite/rude]" (Hutchby 238).

\subsection{Localizing (im)politeness in a conversational encounter}

The analysed ELF extract (in the VIENNA corpus identifiable as LEcon228) represents a conversational encounter in which a student $\left(\mathrm{S}_{1}\right)$ recounts to another student $\left(\mathrm{S}_{2}\right)$ an incident in which s/he was followed in the street by a man into the students' dormitory. As the talk proceeds, the students co-construct their understanding of the problem of safety in and around the students' dormitory. Thus, while the narrative template is "only" a cognitive scheme to render their talk coherent, their main task is social/interpersonal, viz. the establishment of a mutually-shared understanding of the issue, achieving intersubjectivity and consensus.

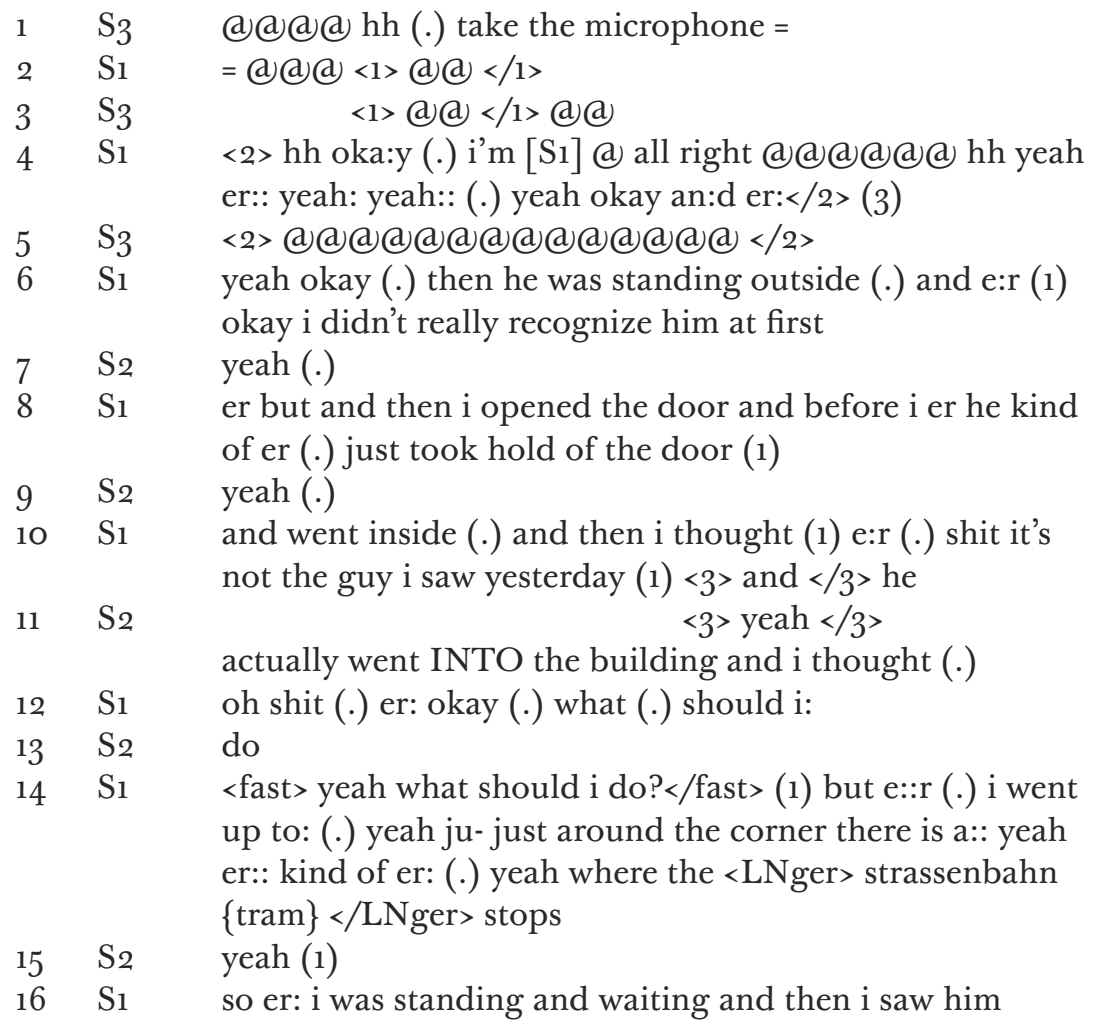


actually (.) walking up the road again (.)

$17 \mathrm{~S}_{2} \quad$ okay $=$

18 S1 = but (.) er yeah i wonder what he was actually doing there

(1) a $<4>$ little bit $</ 4>$ scary actually $=$

$19 \mathrm{~S}_{2} \quad<4>$ he could be $</ 4>$

$20 \mathrm{~S}_{2}=$ yeah (.) because he could be like (.) checking out the place and how he can get in $<5>$ and (.) all that stuff $</ 5\rangle$

$21 \quad \mathrm{~S}_{1}$ $<5>$ yeah he could actually be $</ 5>$ yeah $()<6>$. and i saw him actually $</ 6>$ talking to some people there so (.)

$22 \quad \mathrm{~S}_{2}$ $<6>$ that's really scary $</ 6>$

$23 \quad \mathrm{~S}_{2}$

yeah (2)

$24 \mathrm{~S} 1$

but there is e:r (.) it think there there is a (1) er:: (.) there is a place

$25 \mathrm{~S}_{2} \quad$ yeah $=$

$26 \mathrm{Si} \quad=$ where $($.$) probably e::r ($.$) well a a place where a guard$ could er kind of e:r (.) s- sit (.)

$27 \quad \mathrm{~S}_{2} \quad$ yeah

28 S1 to have e:r b- but there is nobody sitting there now so =

$29 \quad$ S2 $_{2} \quad=$ okay $(1)$

$30 \quad \mathrm{~S} 1$

er: $($.$) i \langle 7>$ don't know $\langle/ 7>$

$3^{1} \quad \mathrm{~S}_{2}$

$<7>$ but you think $</ 7>$ you should maybe like report it to someone o:r $()<1>$. tell $</ 1>$ someone

$32 \mathrm{~S} 1$ $<1>$ yeah:</1>

33 S1 yeah but

$34 \quad \mathrm{~S}_{2}$

i don't if know they will $\langle 2\rangle$ help $\langle/ 2\rangle$ but $<3>$ i $</ 3\rangle$ mean (1)

$35 \quad \mathrm{~S} 1$ $<2>$ yeah $</ 2>$

$36 \quad \mathrm{~S} 1$ $<3>\mathrm{mhm}</ 3>$

$37 \quad$ S1

$3^{8} \quad \mathrm{~S}_{2}$

but (there) is a little bit difficult because e::r (1) there are a lot of people standing outside (.) like =

$39 \quad \mathrm{~S} 1$ $=$ yeah

looking and then you think okay they're (.) going in (like) there is somebody (.) but you never (.) know

$\begin{array}{lll}40 & \mathrm{~S}_{2} & \text { yeah }\end{array}$

$41 \quad$ S1 really: who's er: (2) yeah (.)

$42 \mathrm{~S}_{2}$ but (.) the er the time we were at $<\mathrm{LNger}>$ tigergasse name of a street $\}</$ LNger $>($.

43 S1 yeah 
$44 \mathrm{~S}_{2} \quad$ erm (1) when i left (.) there were a couple of er guys standing outside and i was like oh shit oh shit

45 S1 yeah

46 S2 what am i gonna do now can i GO outside you know are they gonna come in?

47 S1 yeah

48 S2 because i didn't know $<4>$ who $</ 4>$ they were (.)

$49 \mathrm{~S} 1 \quad<4>\mathrm{mhm}</ 4>$

$5 \mathrm{O} \quad \mathrm{S}_{2}$

$51 \quad \mathrm{~S} 1$

$52 \mathrm{~S}_{2}$

$53 \mathrm{~S} 1$

$54 \quad \mathrm{~S}_{2}$

$55 \mathrm{~S} 1$

$56 \quad \mathrm{~S}_{2}$

they didn't look like (.) students to $<5>$ me $</ 5>$

$57 \quad \mathrm{~S} 1$

$5^{8} \quad \mathrm{~S}_{2}$

$59 \quad \mathrm{~S} 1$

but then i just figured well i gotta go out SOMEtimes yeah yeah yeah =

= but they didn't come in

aha okay that's good

yeah (.)

because we have a lot of er in in [placel] er erm (.) at my student home there $=$

a lot of people that e:r (.) yeah have forgot their keys (.)

e:r or something that

$60 \quad \mathrm{~S}_{2}$ yeah

61 S1 yeah (.) so you let (.) let them in i:n but e:r

$62 \quad \mathrm{~S}_{2} \quad$ yeah $($.

63 S1 yeah (.) (they said which) (1)

64 S2 but do you (.) do you know if it was the same guy? (.) you're not sure? (.) or?

65 S1 yeah i i'm er quite sure it was the same $<6>$ guy actually $</ 6>(1)$

$66 \quad \mathrm{~S}_{2}$

$</ 6>$

$<6>$ oh (okay) okay

67 S1 b- but i didn't really (.) e:r (.) i yeah it was i- er: i- er:: it wasn't really e:r before $\mathrm{i}($.$) kind of he had gotten in and \mathrm{i}$ was walking up the street that shit this is not the guy actually $<7>$ that $</ 7>$ e:r $(1)$

$68 \mathrm{~S}_{2} \quad<7>$ yeah $</ 7>$

69 S1 yeah i've seen before and was $<1>$ standing outside $</ 1>$ the window (2)

$70 \quad \mathrm{~S}_{2}$

$$
<1>\text { yeah }</ 1>
$$


$71 \quad S_{1} \quad$ it was (a bit) erm (.)

$72 \mathrm{~S}_{2}$ but what did he do? (.) erm the other day when you saw him (.) like (.)

73 Si $\quad$ yeah $<2>$ he: e::r $</ 2\rangle$

$74 \mathrm{~S}_{2} \quad<2>$ erm how did he $</ 2>$ react? (.)

75 S1 no he: just er: started walking down the street (.)

$76 \quad \mathrm{~S}_{2} \quad$ oh $\langle 3>$ okay $\langle/ 3\rangle$

$77 \quad \mathrm{~S} 1$

$78 \quad \mathrm{~S}_{2}$

$\langle 3\rangle$ and $\langle/ 3\rangle$ i was like (.) what are you doing here $<4>$ (what) $</ 4>$ why did you do that? erm (2)

$79 \quad \mathrm{~S} 1$

$<4>$ yeah $</ 4>$

wow (1) i probably have to be a little careful because i live at the corner so $($.$) i have three windows as well =$

$80 \quad \mathrm{~S}_{2} \quad=$ yeah $($.

$81 \quad \mathrm{~S}_{1} \quad$ er (.) the other people have er one window

$82 \quad \mathrm{~S}_{2} \quad$ yeah

83 S1 so: e:r (.) (a) < (a) > yeah </(a) > it's a little bit erm (2) er (1)

$84 \quad \mathrm{~S}_{2} \quad$ you have to go to the $<$ LNger $><$ spel $>$ oe a d $</$ spel $>$ \{austrian academic exchange service $<</ \mathrm{LNger}>$ and say $<5>$ that it's not save to live there give me $</ 5>$ a room at $<$ LNger $>$ tigergasse $\{$ name of a street $\}</$ LNger $>=$

$85 \quad \mathrm{~S}_{1} \quad<5>$ yeah (a) (a) yeah yeah yeah $</ 5>$

$86 \mathrm{~S} 1 \quad=\langle$ (a) $\rangle$ yeah $\langle 6\rangle$ i think so $\langle/ 6\rangle\langle/$ (a) $\rangle$

$87 \quad \mathrm{~S}_{2}$

$88 \quad \mathrm{~S}_{1}$ $<6>$ (a)(a) $</ 6>\mathrm{hh}$

$89 \quad \mathrm{~S}_{2} \quad$ yeah $($.

$90 \quad S_{1} \quad$ yeah (.) er (1) erm (1) but e::r (1) yeah (.) i would like to: (.) yeah just (.) it's such a: (.) it's such far from where i live (.)

$91 \quad \mathrm{~S}_{2} \quad$ yeah

92 S1 to get home now $i$ have to take the night bus or something er so (3) erm $()<7>$. diffi $</ 7>$ cult

$93 \quad \mathrm{~S}_{2}$ $<7>$ er h- $</ 7>$

$94 \quad \mathrm{~S}_{2} \quad$ how do you get home from the city center do you take a $<$ LNger $><$ spel $>\mathrm{u}<$ /spel $>$ bahn? $\{$ underground $</$ LNger $>$ or a tram or $($.

95 S1 e:r (.) well e:r during the daytime (.) now i took to t- er $<$ fast $>$ when i came here now i took the number five $</$ fast $>$ 


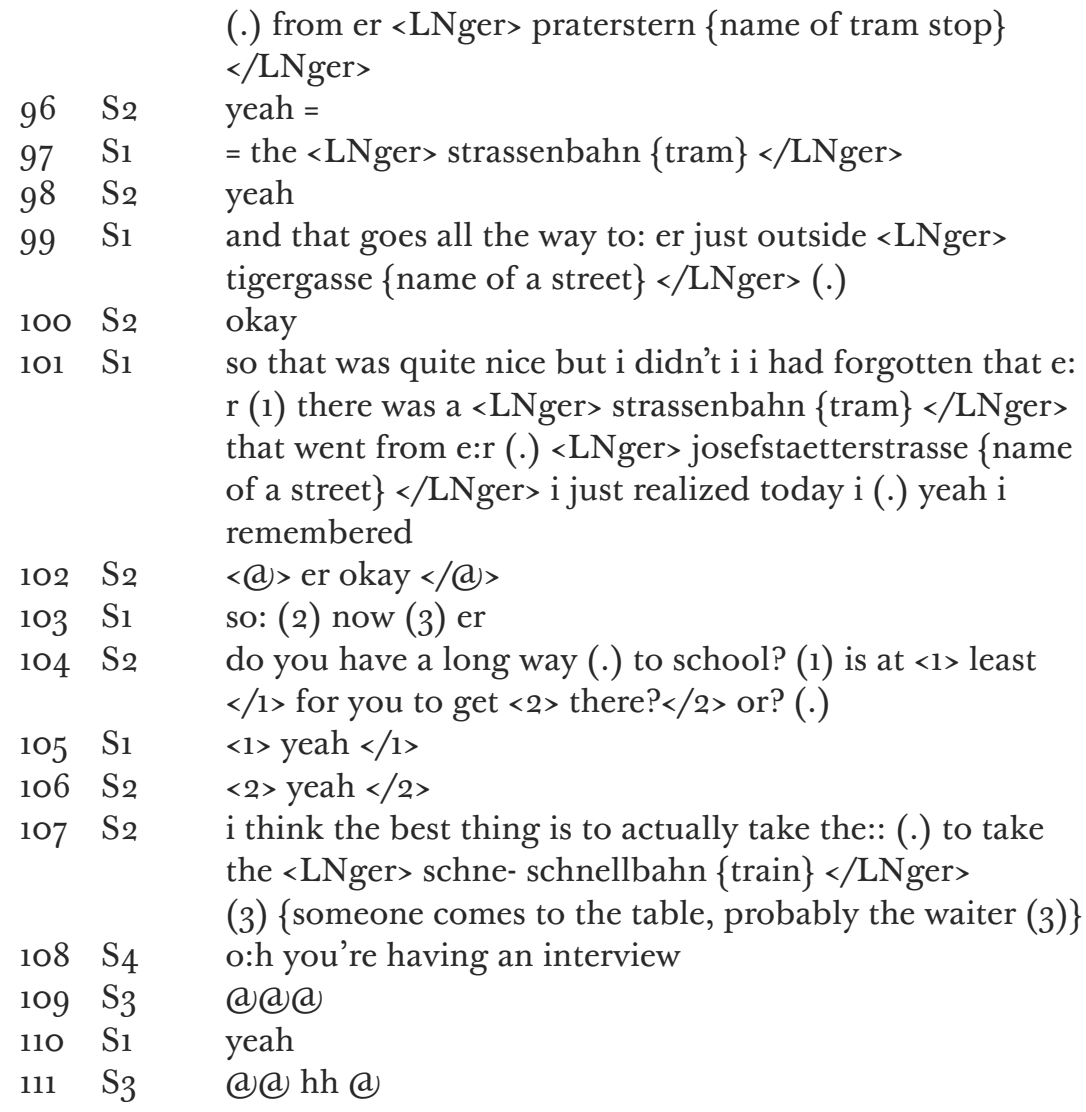

In general, the inherent problem of the analysis of the politeness aspects of similar naturally occurring interactions is that their participants rarely overtly, if at all, comment on each other's behaviour and assign it evaluative labels such as (im)polite, rude, aggressive, etc., hence they do not produce what Eelen

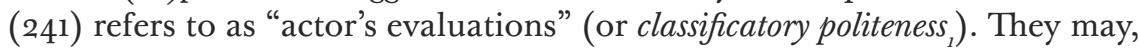
however, produce what he calls "actor's expressive behaviour" (or expressive politeness ${ }_{1}$ ), i.e., lexicogrammatical structures "traditionally" associated with polite language, such as formulaic tokens of politeness (e.g., please, sorry, etc.), honorifics, conventionally indirect requests and many others. While the mainstream (pragmatic) politeness researchers engage themselves exactly in identifying, listing and surveying these expressions, and, once they are 
located, passing judgements on the presence and/or absence of politeness, the postmodernist/postpragmatic approach relegates these judgements to the participants themselves and resorts to locating possible loci in the ongoing interactions where such judgements may have taken place. Adopting the latter approach in the present paper I argue that, rather than enumerating the instances of expressive politeness, including please as a quintessential politeness formula, and claiming that their use automatically guarrantees polite intentions, analysts should look for possible participants' evaluations of each other's behaviour as (im/over)polite, rude, etc., which are potentially dispersed across the entire span of the event's relational work and which take up much subtler, unobtrusive forms and practices.

To discern what counts as "surplus" to and/or what goes beyond the expected behaviour in a given social encounter, the participants resort to their experience accumulated over their previous history of participation in similar types of social encounters. Watts, following Bourdieu, uses the notion of habitus to account for "the set of dispositions to behave in a manner which is appropriate to the social structures objectified by an individual through her/his experience of social interaction" (Watts 274) and relates it to his politic behaviour (cf. Figure 2) which includes "the knowledge of which linguistic structures are expectable in a specific type of interaction in a specific social field" (Watts 161). In an attempt to explicitely formulate participants' tacit knowledge and experience with their participation in casual conversational encounters built upon a narrative template, I utilize Goffman's notion of "participation framework" which links participants' discursive roles, the associated lines of their participation and faces which participants offer to be (preferably) accepted (Figure 4).

\begin{tabular}{|c|c|c|}
\hline & \multicolumn{2}{|l|}{ discursive role } \\
\hline & narrator & narratee \\
\hline line & $\begin{array}{l}\text { narrates, follows the narrative template, } \\
\text { stays on point, checks the comprehension } \\
\text { by the narratee }\end{array}$ & $\begin{array}{l}\text { monitors narration, } \\
\text { acknowledges, } \\
\text { offers feedback }\end{array}$ \\
\hline face & $\begin{array}{l}\text { competent storyteller (possesses narratorial } \\
\text { skills), worthy of being listened to, } \\
\text { considerate towards the narratee }\end{array}$ & $\begin{array}{l}\text { attentive, interested, } \\
\text { involved, active listener }\end{array}$ \\
\hline
\end{tabular}

Figure 4: Participation framework for the analysed conversational encounter 
It is to be noted that this framework emerges through the participants' involvement in every occasion of a narrative-based talk in which it is constantly (re)produced, and that it is flexible to accommodate potential genre shifts, hence it is inherently negotiable. Thus I argue that the description of the participants' roles provides for their expectations of an appropriate, neutral, hence non-polite behaviour. Any forms of behaviour which depart from this reference point in the direction towards the positive or negative pole of their relational work are open to the participants' positive and/or negative evaluations as (im)polite/rude, etc. It is the location of the sites where these evaluations take place and the discussion of how the attributions of politeness may be carried out which is in the focus of the following section.

\subsection{Discussion}

Despite the fact that English is a native language for neither of the two participants, the progression of the conversation suggests that they manage to co-construct a fluently flowing and mutually intelligible discourse without having to solve apparent misunderstandings and/or problems. Overall, they re-produce the participation framework of a narrative conversational encounter by taking up the lines of behaviour whereby they co-construct their discourse identities of a narrator and a narratee respectively. The lines are represented by the activities bound to these categories and include esp. the narrator's access to an uninterrupted floor while recounting them the story and the narratee's sending her feedback while acknowledging its receipt. It may be recalled that the negotiated participation framework serves both participants as a background against which they evaluate the (un)markedness, and (in)appropriateness, of each other's interactional and discursive behaviour and assign it the values of (im)politeness/rudeness, etc., in case they evaluate it as deviating from that background. An immediately noticeable aspect of their behaviour is that, while being engaged in relational work, they produce no overt linguistic signals of the presence and/or absence of politeness - they use no routine politeness formulae whatsoever; in other words, they employ neither expressive nor classificatory politeness. What this non-presence of overt tokens of politeness (ritualized expressions) suggests is, however, not that they behave towards each other impolitely (I refer here to the "traditional" either/or binaristic approach where the absence of politeness entails impoliteness), nor that politeness is absent altogether, but rather that the speakers' potential (im)polite/rude, etc., intentions surface in the hearers' interpretations/evaluations. As a detached observer/analyst all 
I can do is to point out those spots in the evolving interaction where these hidden attributions of (im)politeness as going beyond the expectable may have taken place and characterize them.

The fast growing ELF research has pointed out, among other things, that "ELF talk seems to be qualitatively different in nature" (House 567) and that, contrary to general expectations, it is marked by fewer misunderstandings, since participants are striving to maximize intelligibility and downplay trouble, for example, through the operation of what Firth calls the "let-itpass" and "make it normal" principles. The conversational data suggest that participants appear to actively collaborate on achieving intelligibility of their turns and employ strategies aimed at pre-empting possible misunderstandings and trouble. Among these "pro-active" communicative strategies are those attending to the efficient operation of the turn-taking mechanism and ensuring thereby a smooth channel:

1. speakers adhere to the "one-at-a-time" principle strictly - overlaps are rare, short and quickly resolved, for example by the overlapper quickly dropping her overlapping turn (19),

2. speakers closely monitor each other's elaboration of turns and send frequent supportive back-channel signals, esp. yeah $(7,9,11,15,53)$ and okay (17); what is more, they seem to employ every opportunity to do so $(6-12,22-30,42-56)$,

3. although speaker-transfer proceeds at transition-relevant places, hence it is sensitive to the turn-yielding signals $(31,42)$, as a rule it tends to be abrupt and/or unhedged $(84,94,104)$ and employs stereotypical means of signalling takeover, cf. S2's but initiating advice-giving (31), narrative (42) and questions $(64,72)$,

4. speakers frequently use hesitations and long pauses, repetitions $(28,64)$, restatements (31), self-repairs $(67,95)$,

5. participants choose a "safe" topic which has a high potential of both mutually shared referential content and of a possibility to approximate their perspectives.

Despite the appearance of an overall robustness of the talk, which is also manifested in the absence of metacommunicative signals (discourse markers) and ritual formulae, the parties evidently manage to build and sustain a cooperative mode of interaction. In fact, many ELF studies find cooperation as a principal feature of ELF interaction (cf. Meierkord), which leads to the observation that cooperation is actually the norm, i.e., the expected, 
unmarked, hence non-polite/politic type of behaviour which, as I claim, can be described within the participation framework for the given situation. The question that now arises is whether there is any behaviour which would suggest that either participant is going beyond this expectable norm and which would be interpretable as being polite, i.e., as a demonstration of her positive concern for the partner's needs. I suggest that there are indeed several locations in the flow of the conversation where attributions of polite intentions may have occurred. They all involve the instances of the narratee's behaviour who may be seen as taking lines whereby she does more than what is expected of her discursive role (see Figure 4). They demonstrate that the conversational encounter emerges through the joint active effort of both participants.

First, in turn 13, as a demonstration of her close monitoring the narration and of her active involvement in its co-construction, the narratee $\left(\mathrm{S}_{2}\right)$ produces what may be an instance of a "recognitional interruption", i.e., a non-transgressive interruption which is evaluated as an affiliative rather that confrontational resource (cf. Ferenčík 101) and which is manifested by her supplying a recognized constructional unit, the verb $d o$. That this move is evaluated as supportive is demonstrated by the narrator's building the material into the ensuing turn structure (yeah what should $i d o$, line 14).

Another telling demonstration of a collaborative turn production occurs in turns 18-21 where the participants co-construct the identity of the potential culprit: by re-using identical structure (he could be 19, 20, 21) they align their perspectives and build consensus. Also, the narratee's that's really scary (20) is an instance of what in the ELF literature has been described as a "represent/ echoing/mirroring/shadowing" (cf. House 568), which is a multifunctional strategy which, by restating a part of the narrator's previous turn (18) and explicitely acknowledging it serves the purpose of empathizing with the speaker and of enhancing discourse coherence.

The following are examples of sequences which demonstrate that $\mathrm{S}_{2}$ adopts two lines of behaviour which go beyond those described in the participation framework for her role of a narratee and which are thus open to the narrator's evaluation as a "surplus" phenomenon, viz. as polite, in that they enhance her positive face wants: she offers advice (turns $31,84,107$ ) and asks questions (turns $64,72,94,104$ ). From the politeness perspective it is symptomatic that the trajectories of the two advice-giving sequences $(31-36,84-93)$ contain at least a partial acceptance as a preferential follow-up, whereby both parties' face wants are satisfied. Also, the awareness of the face-threatening potential of the advice (you should maybe like report it to someone or tell someone; 31 ) and a 
need to ameliorate it is demonstrated in the use of a hedge (like) and modality (modal adverb maybe), which render it more as a suggestion. The second advice (you have to go to the oead and say that it's not save to live there; 84) construed rather as an urge displays S2's concern for S1's safety.

The progression of the four question-answer sequences demonstrate that the "answerhood" is more of a joint problem than merely the answerer's responsibility and, accordingly, that it is established collaboratively. With a view of a general preference for acceptance of answers, S2's question formulation accommodates a possible answerer's uncertainty while making room for the answerer's own elaboration: do you know if it was the same guy? you are not sure? or? (64); do you have a long way to school? is at least for you to get there or? (104), or recasts a wh-question to a yes/no question: how do you get home from the city center do you take a u bahn? or a tram or (94), or at least narrows down its focus to make it easier to answer: what did he do? (.) erm the other day when you saw him (.) like (.) erm how did he react? (72-74). The ways these questions are formulated display the questioner's effort to demonstrate her awareness of their face-threat potential and as such may have been open to the answerer's evaluation as polite.

Finally, to contribute to the establishment of the overall atmosphere of solidarity, unobtrusiveness and empathy speakers use cajolers (I mean, you know), expletives (shit), and supportive laughter (1-5, 83-87, 109-111).

In conclusion, it is the collaborativeness of the participants in the production of discourse which is a foremost feature of the analysed ELF conversation and which permeates all levels of its organization. The observation is consonant with some ELF research results suggesting that "NNS-NNS conversations are cooperative, consensus-oriented and mutually supportive" (Grzega 51). It may be hypothesized that it is the inclination towards the co-operative pole of interaction that characterizes unstable, fluctuating and ephemeral communities of ELF speakers which seems to be their single most important feature and which lies in the centre of ELF (im)politeness. Further, it may be the case that ELF politeness is not a stable and homogeneous entity but rather an amalgam of strategies and procedures which emerges with every instance of ELF interaction anew and which results from the speakers' "ELF identity" as well as from their respective L1 identities. These norms are "glocal" (they result from speakers' local and global identities) and fluid as particular ELF communities are. Also, they are constantly negotiated to secure primarily an intelligible transfer of "cognitive" meanings in international encounters (cf. ELF as a "language for communication"; House 559), and to attend to speakers" 
interpersonal needs (cf. a "language for identification"; House 56o) which are no less important since ELF speakers do not come from a social vacuum who turn off their respective Li linguacultures. Rather, ELF represents a means of their "secondary socialization" into the world's multilingual settings. In the light of these observations, the dynamically evolving and ephemeral ELF settings remain an under-researched area which offer themselves as a fruitful area for the application of post-modern politeness approaches in conjunction with social-theoretical notions of community of practice.

\section{Conclusion}

A great majority of the present world's multicultural discourse takes place in ELF settings in which interlocutors employ English as a common code to attain both communicative and social goals. These settings are the terrain upon which temporary communities of practice flexibly emerge and dissolve and whose members creatively draw on the repertoire of resources available to them through the use of ELF and their respective Lis. English language as a common linguistic denominator is shaped by the immediate communicative purposes which arise in inherently multicultural ELF settings and in which it plays the role of a functional variety (register) ensuring not only message intelligibility but also attainment of social goals, such as mutual understanding, co-operation and consensus.
Abbreviations
CofP Community of Practice
ELF English as a Lingua Franca
EFL English as a Foreign Language
ENL English as a Native language
ESL English as a Second Language
FTA face-threatening act
L1 first/native language
L2 second language
NS native speaker
VOICE Vienna-Oxford International Corpus of English

\section{Transcription symbols}

(.) (1) pause (and its length in seconds) 
MILAN FERENČÍIK

$$
\begin{array}{ll}
= & \text { latching } \\
<6></ 6> & \text { overlap beginning and end } \\
: & \text { vowel length } \\
\text { (a)@ } @ & \text { laughter } \\
<\text { LNger }> & \text { last name (in German) }
\end{array}
$$

"This publication is the result of the implementation of the project Retrofitting and Extension of the Center of Excellence for Linguaculturology, Translation and Interpreting supported by the Research \& Development Operational Programme funded by the ERDF."

\section{Works Cited}

Bourdieu, Pierre. The Logic of Practice. Cambridge: Polity Press, 1990. Brown, Penelope and Stephen Levinson. "Universals in language usage: Politeness Phenomena." Questions and Politeness: Strategies in Social Interaction. Ed. Esther N. Goody. Cambridge: Cambridge University Press, 1978. 56289 .

--. Politeness, Some Universals in Language Usage. Cambridge: Cambridge University Press, 1987.

Eckert, Penelope and Sally McConnell-Ginet. "Think practically and look locally: language and gender as community-based practice." Annual Review of Anthropology. 21, 1992: 461-490.

Eelen, Gino. A Critique of Politeness Theories. Manchester: St Jerome, 2001.

Ferenčík, Milan. Doing (Im)politeness in the Media. Prešov: FF PU, 2010.

Ferguson, Charles A. "Linguistic Diversity in South Asia." Language Structure and Use. Essays by Charles A. Ferguson. 196o. Ed. Anwar S. Dil. Stanford, CA: Stanford University Press, 1971. 26-49.

Firth, Alan. "The discursive accomplishment of normality. On 'lingua franca' English and conversation analysis." Journal of Pragmatics. 26, 1996: 237259 .

Gibová, Klaudia. O preklade anglických právnych textov EÚ. Prešov: Vydavatel'stvo Prešovskej univerzity, 2010.

Goffman, Ervin. Interaction Ritual: Essays on Face-to-Face Behaviour. New York: Doubleday Anchor Books, 1967.

---. Forms of Talk. Philadelphia: University of Pennsylvania Press, 1981.

Graddol, David. English Next. British Council 2006. 14 May 2012 $<$ http://www.britishcouncil.org/learning-research-english-next.pdf>. 
Grzega, Joachim. "Reflections on Concepts of English for Europe. British English, American English, Euro-English, Global English." fournal for EuroLinguistiX. 2, 2005: 44-64.

Halliday, Michael A.K. Language as a Social Semiotic: The Social Interpretation of Language and Meaning. London: Edward Arnold, 1978.

Haugh, Michael. "The discursive challenge to politeness research: An interactional alternative." Journal of Politeness Research. 3, 2007: 295-317.

House, Juliane. "English as a lingua franca: A threat to multilingualism?" Journal of Sociolinguistics. 7/4, 2003: 556-578.

Hutchby, Ian. "Participants' orientations to interruptions, rudeness and other impolite acts in talk-in-interaction." Journal of Politeness Research. 4, 2008: 221-241.

Jenkins, Jennifer. World Englishes. A Resource Book for Students. London: Routledge, 2009.

Jenkins, Jennifer, Marko Modiano and Barbara Seidlhofer. "Euro-English." English Today. 17 (4), 2001: 13-19.

Kachru, Braj, B. "Standards, codification and sociolinguistic realism: the English language in the outer circle." English in the World: Teaching and Learning the Language and Literatures. Ed. Randolph Quirk and Henry G. Widdowson. Cambridge: Cambridge University Press, 1985.

---. "Teaching World Englishes." The Other Tongue: English across Cultures. 2nd edition. Ed. Braj B. Urbana: University of Illinois Press, 1992.

Lakoff, Robin. "The logic of politeness; or minding your p's and q's." Papers from the Ninth Regional Meeting of the Chicago Linguistic Society, 1973: 292-305.

Leech, Geoffrey. Principles of Politeness. London: Longman, 1983.

Locher, Miriam A. Power and Politeness in Action: Disagreements in Oral Communication. Berlin/New York: Mouton de Gruyter, 2004.

---. "Polite behaviour within relational work: the discursive approach to politeness." Multilingua. 25 (3), 2006: 249-267.

Locher, Miriam A. and Richard J. Watts. "Politeness theory and relational work." Journal of Politeness Research: Language, Behaviour, Culture. 1(1), 2005: 9-33.

Mauranen, Anna. "The Corpus of English as Lingua Franca in Academic Settings." TESOL Quarterly. 37 (3), 2003: 513-27.

McArthur, Tom. The English Languages. Cambridge: Cambridge University Press, 1998.

Meierkord, Christiane. "Interpreting successful lingua franca interaction. An 
analysis of non-native/non-native small talk conversations in English." Linguistik online 5, 1/10. 14 May 2012 <http://www.linguistik-online.com/1_oo/MEIERKOR.HTM>..

Modiano, Marko. "International English in the global village." English Today. 15/2, 1999: 22-34.

--.. "Standard English(es) and educational practices for the world's lingua franca." English Today. 15 (4), 1999: 3-13.

Mollin, Sandra. "English as a Lingua Franca: A New Variety in the New Expanding Circle?" Nordic fournal of English Studies. 5 (2), 2006: 41-57.

Murray, Heather. "Swiss English Teachers and Euro-English: Attitudes to a Non-Native Variety." Bulletin suisse de linguistique appliquée. 77, 2003: $147^{-175}$.

Seidlhofer, Barbara. "A Concept of International English and Related Issues: From 'Real English' to 'Realistic English'?" Council of Europe Conference Paper. Strasbourg, 2002. 14 May 2012 <http://www.coe.int/T/DG4/Linguistic/Source/SeidlhoferEN. pdf\#xml=http://thunderstone.coe.int/texis/ThunderstoneSearchService/ pdfhi.txt?query=seidlhofer\&pr=Internet_D $4 \&$ prox=page\&rorder $=500 \& r$ prox $=500 \&$ rdfreq $=500 \&$ rwfreq $=500 \&$ rlead $=500 \&$ rdepth $=250 \&$ sufs $=1 \&$ ord er $=$ r\&cq $=\&$ rpp $=10 \& i d=4 \mathrm{dd} 7784 \mathrm{~b} 28>$.

---. "Research perspectives on teaching English as a lingua franca." Annual Review of Applied Linguistics. 24, 2004: 209-39.

Strevens, Peter. "English as an international language: directions in the 199os." The Other Tongue: English across Cultures. Ed. Braj B. Kachru. Urbana: University of Illinois Press, 1992.

Terkourafi, Marina. "Beyond the micro-level in politeness research." Fournal of Politeness Research. 1(2), 2005: 237-262. VOICE. The Vienna-Oxford International Corpus of English. 14 May 2012 $<$ http://www.univie.ac.at/voice/>.

Watts, Richard J. Politeness. Cambridge: Cambridge University Press, 2003.

Watts, Richard et al. Politeness in Language. Studies in its History, Theory and Practice. 2nd edition. Berlin and New York: Mouton de Gruyter, 2005.

Wenger, Etienne. Communities of Practice. Learning, Meaning and Identity. Cambridge: Cambridge University Press, 1998.

Young, Richard. Language and Interaction. London and New York: Routledge, 2008. 